\title{
A LEGITIMIDADE DE NORMAS DE DIREITO INTERNACIONAL: UM DIÁLOGO COM THOMAS FRANCK
}

Felipe Kern Moreira

\section{RESUMO}

O OBJETIVO DESTE ARTIGO É DEBATER A NOÇÃO DE LEGITIMIDADE DE NORMAS DE DIREITO INTERNACIONAL PÚBLICO PROPOSTA PELO JURISTA E PROFESSOR DA UNIVERSIDADE DE NOVA YORK, THOMAS FRANCK. ESTA CONTRIBUIÇÃO CONSISTE NA PROPOSTA TEÓRICA E MULTIDISCIPLINAR DE DESCREVER DE QUE FORMA A LEGITIMIDADE DE NORMAS JURÍDICAS INTERNACIONAIS PODE SER AVALIADA A PARTIR DE CRITÉRIOS DE PEDIGREE ESPECÍFICOS. ALÉM DE TRATAR DA LEGITIMIDADE COMO DETERMINAÇÃO, VALIDAÇÃO SIMBÓLICA, COERÊNCIA E ADERÊNCIA, PROCURA RESPONDER POR QUE A JUSTIÇA NÃO SERIA UM CRITÉRIO DE QUALIFICAÇĀO DE LEGITIMIDADE DE NORMAS INTERNACIONAIS.

\section{PALAVRAS-CHAVE}

LEGITIMIDADE; NORMAS INTERNACIONAIS; THOMAS FRANCK, JUSTIÇA.

\section{ABSTRACT}

THE AIM OF THIS ARTICLE IS TO DEBATE THE NOTION OF LEGITIMACY OF NORMS OF PUBLIC INTERNATIONAL LAW AS PURPOSED BY THE LAWYER AND PROFESSOR OF NEW YORK UNIVERSITY, THOMAS FRANCK. THIS CONTRIBUTION CONSISTS ON A THEORETICAL AS WELL AS MULTIDISCIPLINARY PURPOSE IN ORDER TO DESCRIBE HOW THE LEGITIMACY OF NORMS OF INTERNATIONAL LAW COULD BE EVALUATED THROUGH SPECIFIC PEDIGREE CRITERIA. BEYOND THE CRITERIA OF DETERMINATION, SYMBOLIC VALIDATION, COHERENCE AND ADHERENCE, THIS EFFORT CONCERNS TO ANSWER WHY THE FAIRNESS WOULDN'T A CRITERION FOR THE QUALIFICATION OF LEGITIMACY IN TERMS OF INTERNATIONAL LAW NORMS.

\section{KEYWORDS}

LEGITIMACY; INTERNATIONAL LAW NORMS; THOMAS FRANCK; FAIRNESS.

\section{INTRODUÇÃO}

O propósito deste artigo é tornar conhecida a noção de legitimidade de normas no plano internacional formulada por Thomas Franck, ao que, quando oportuno, acrescentar comentários de forma a estabelecer a interlocução entre este autor e outras contribuições relacionadas aos temas tratados. Thomas M. Franck foi professor da New York University Scholl of Law ${ }^{1}$ e é tido por alguns como expoente da suposta "Escola de Manhattan", conjunto de pesquisadores dedicados à reflexão sobre direito internacional e tributário da obra de Louis Henkin, em particular o livro How Nations Behave no qual destaca-se a ênfase metodológica de análise na perspectiva do comportamento de Estados no sistema internacional. 
Escola de Manhattan é uma terminologia possível para se referir a pesquisadores da Universidade de Nova York dedicados ao direito internacional e influenciados pelas ideias de Thomas Franck. Sobre isso, David Kennedy publicou o artigo "Tom Franck and the Manhattan School" na forma de uma homenagem a quem considerou o Andy Warhol do direito internacional norte-americano no pós-guerra. ${ }^{2}$ Isto se deve em parte ao reconhecimento da produção intelectual de Thomas Frank relativa ao direito internacional, desde os anos 1960, frente às diferentes posturas do governo norte-americano. O termo “escola”, neste caso, talvez seja generoso e não pressupõe cânones metodológicos estanques e sim referência a um grupo de colegas de trabalho com ideias em comum quanto à plausibilidade e à relevância do direito internacional, materializadas na obra Introduction to International Law: Cases and Materials, de Henkin, Pugh, Schachter, Smit e Damosch. ${ }^{3}$

Thomas Franck exerceu influência intelectual notável dentre seus pares, particularmente do final dos anos 1950 até parte dos anos 1960 e depois nos anos 1980, perpassando os anos do governo Clinton. ${ }^{4}$ A Escola de Manhathan reúne nomes como Oscar Schachter, Wolfgang Friedmann, Louis Henkin, Theodor Meron, e é possível delinear alguns eixos comuns nas ideias desses autores: orientação pela norma, e a aceitação sociológica da lei, ${ }^{5}$ o liberalismo jurídico e o acompanhamento não indiferente dos principais temas da agenda de política internacional americana. Outro traço comum entre os autores da denominada Escola de Manhathan é a ênfase da análise no comportamento de Estados, que se percebe, por exemplo, nos estudos reativo-comportamentais de Estados (Henkin) ou no papel do costume para formação do direito internacional $^{6}$ (Schachter e Meron). Essas agendas refletem a recorrrente performance de autonomia ética estatocêntrica e voluntarista, percebida na prática e no pensamento do direito internacional norte-americano.

São necessárias ainda algumas linhas sobre determinadas opções metodológicas deste texto. A diversidade de interesses e a abertura disciplinar de Thomas Franck dificultam a escolha do recorte de autores e teorias para colocar ideias em perspectiva. Não é intenção deste artigo utilizar balizamento teórico específico. O fato da proposta teórica de Franck ser centrada na norma jurídica e na aproximação teórico-jurídica descritiva, sugere que o debate privilegie as assunções do positivismo jurídico austiniano, kelseniano e hartniano. A utilização enfática da terminologia “pedigree” e também o tratamento crítico do positivismo hartiniano propiciam a referência à obra de Ronald Dworkin. Autores importantes ficarão fora do diálogo a fim de concentrar o foco na descrição crítica da ideia de legitimidade como propriedade da norma. Outros autores mencionados no texto, como David Kennedy, Carl Schmidt, Nicolas Onuf, John Rawls, Gunther Teubner, são resultado de minha seleção com o objetivo de ajustar o foco nos conceitos de Thomas Franck.

Por que estudar as ideias do professor Thomas Franck? Primeiro, por causa do método: para tomar conhecimento que legitimidade pode ser estudada a partir da perspectiva normativa, presumidamente, jurídica. Segundo, porque legitimidade é 
um fator decisivo para a existência de normas jurídicas, não obstante, aqui, a ênfase esteja em normas de direito internacional público. Terceiro porque a influência intelectual de Thomas Franck dentre os schoolars norte-americanos foi notável. Nesses termos, compreender sua literatura é um passo para entender parte da perspectiva liberal do direito internacional conforme é compreendido, ensinado e levado a efeito nos Estados Unidos.

Legitimidade é um conceito associado comumente ao consenso político ou social. Thomas Franck compreende-o de forma particular. Para ele, legitimidade é a percepção de que normas possuem qualidades ou propriedades que lhes conferem atração em direção ao cumprimento por parte dos destinatários. Em que medida a legitimidade pode ser entendida como propriedade e quais características lhe confere maior ou menor percepção (de legitimidade) são os temas debatidos nesta contribuição.

\section{LEGITIMIDADE COMO PROPRIEDADE DA NORMA INTERNACIONAL}

Em 1988, Thomas M. Franck, professor emérito da New York University Scholl of Law, publicou no American Journal of Internacional Law o artigo "Legitimacy in Internacional System” e, em 1990, uma versão expandida e aperfeiçoada das ideias reunidas no livro The Power of Legitimacy Among Nations. As considerações deste artigo baseiam-se, principalmente, nesses dois textos.

O texto de 1988 começa enfatizando que é surpreendente que as nações, na maior parte do tempo, obedeçam normas de direito internacional em suas relações com outros Estados. Franck estudou por que Estados obedecem ao direito internacional na abstenção do elemento coercitivo e, ainda, procurou determinar por que, e em que circunstâncias, uma regra específica é obedecida. ${ }^{7}$ Nas palavras de Gelson Fonseca Júnior, a iniciativa de Franck foi, resumo, a seguinte:

... existe, pelo menos, a possibilidade hipotética de que, se alguém conseguir demonstrar que há regras que são habitualmente obedecidas nas relações internacionais, então será capaz - e, na verdade, só assim será capaz -, de compreender esse fenômeno postulando um fator instrumental não austiniano; um que não seja um comando soberano, nem seja aplicado coercivamente, nem mesmo obedecido somente pela razão ou pelo interesse próprio de obter uma recompensa em curto prazo, já que isso não explica um respeito verdadeiro a regras que nem sempre beneficiará igualmente todas as partes em interação. ${ }^{8}$

O problema a ser enfrentado por Franck é, em primeiro lugar, aplicar o conceito de legitimidade ao campo do direito internacional. O que aqui se denomina "fator instrumental austiniano" diz respeito ao tratamento dado ao conceito de legitimidade no 
plano do Estado nacional, o qual, na história das ideias no continente europeu, sofreu memorável influência das reflexões seminais do jurista John Austin. ${ }^{9}$ No comentário de Gelson Fonseca Júnior, Thomas Franck assume o pressuposto do cumprimento de normas internacionais, o que o comentarista trata como hipótese. ${ }^{10}$

Franck propõe que é possível falar em legitimidade no plano normativo do direito internacional. Considerando a falta do elemento coercivo - de forma geral - na dinâmica das regras internacionais, ele tenta demonstrar que é possível aprender coisas a respeito de legitimidade que não poderiam ser desvendadas com a observação de seus efeitos sobre o comportamento de indivíduos num dado Estado. Assim, o estudo da legitimidade de normas no direito internacional distancia-se do conceito de validade e permite a perspectiva privilegiada que ultrapassa o contexto da autonomia e da autoridade constitucional do Estado.

Ao questionar por que os Estados cumprem normas frente à inexistência de um sistema sofisticado de sanções, ele propõem que é possível desvincular esse tipo de agenda de pesquisa das questões afetas às fontes da obrigação normativa. Em termos gerais essa iniciativa científica pode ser traduzida como procurar isolar a motivação do comportamento estatal para além da assunção deontológica que Estados cumprem normas porque pactuaram previamente de boa-fé nesse sentido.

Em termos específicos questiona-se por que e sob quais circunstâncias uma regra específica é observada, pergunta que Franck procurou responder em artigo publicado em 1988. A respeito de legitimidade, Franck mencionou o conceito que marca o início de uma ideia original na literatura jurídica, até então, a de legitimidade como qualidade da norma:

Legitimacy is used here to mean that quality of a rule which derives from a perception on the part of those to whom it is addressed that it has come into being in accordance with right process. Right process includes the notion of valid sources but also encompasses literary, socio-anthropological and philosophical insights. The elements of right process (...) are identified as affecting decisively the degree to which any rule is perceived as legitimate. ${ }^{11}$

No livro de 1990, o conceito sofre modificações:

Legitimacy is a property of a rule or rule making institution which itself exerts a pull toward compliance on those addressed normatively because those addressed believe that the rule or institution has come into being and operates in accordance with generally accepted principles of right process. ${ }^{12}$

Na primeira citação, legitimidade é qualidade - posteriormente o autor opta pelo termo propriedade - da regra que remete o conceito ao campo jurídico. A palavra 
percepção - que desaparece no conceito instrumental no livro - descreve o modo como os sujeitos para os quais a norma é dirigida/aplicável entendem que essa norma existe e é válida e, portanto, exigível. Outra particularidade é a menção aos elementos do devido processo, os quais qualificam normas segundo um gradiente de legitimidade.

Parece não ter sido registrada por Thomas Franck - até onde foi o alcance da literatura pesquisada - nota sobre as causalidades ou motivações das diferentes versões nos conceitos de 1988 e 1990. O conceito de 1988 é mais extenso e mais aberto transdisciplinarmente. Pode ser que o autor tenha desejado tornar seu conceito mais enxuto, mais preciso, mais elegante, menos falível ou mais científico. A mudança do termo qualidade para propriedade muda o eixo compreensivo, de uma descrição, de uma característica, para a potencialidade de realizar.

Outra notável modificação nos conceitos é que o de 1988 coloca a ideia de legitimidade no campo da percepção e o de 1990 enfatiza a crença dos destinatários de que regras e instituições foram criadas de acordo com princípios de direito amplamente aceitos. A esse respeito, Franck não utiliza a expressão "due processo of law" que diz mais respeito às garantias e ao aspecto processual do que à faculdade de produzir normas válidas.

Muito se poderia escrever sobre as diferenças nas versões que o próprio autor preferiu não comentar. Talvez, as diferentes palavras e significações dos conceitos de legitimidade não modifiquem a integridade teórica a qual possui ênfase nos diferentes tipos de propriedades.

A menção ao termo crença permite ponderar que a segunda definição pode ser caracterizada como weberiana, no sentido de legitimidade como crenças compartilhadas, muito embora Weber fale da legitimidade de uma ordem e Franck fale de legitimidade como propriedade da norma. O conceito de legitimidade de Max Weber diz respeito tanto às convenções sociais quanto ao sistema jurídico, o que, nesse último caso, é ser caracterizado, pela probabilidade de coação. ${ }^{13}$ A coação, contudo, não será o fundamento da legitimidade de normas de direito, apesar de ser sua função forçar a observação de determinada ordem ou castigar por sua violação. A garantia da legitimidade dirá respeito, no campo do direito positivo - que difere do campo da afetividade ou religiosidade -, à crença na vigência de valores supremos e obrigatórios relativos à moral e à estética, relacionados, então, ao elemento racional de garantia da legitimidade. Por isso, é importante reconhecer diferenças na definição teórica de "legitimidade" segundo os campos jurídico e sociológico:

Weber defined legitimacy in empirical terms as "belief in legitimacy". Where political subjects recognize rule as legitimate, he argued, it can be considered legitimate. In keeping with his commitment to value-free social science, Weber did not consider some foundations of legitimacy superior to others. His approach to legitimacy as an empirical, not a normative, matter informed much subsequent research. ${ }^{14}$ 
Os estudos de Max Weber sobre legitimidade constam como referência para diversos exercícios de pesquisa posteriores; seu contexto científico diz respeito à preocupação com o esforço de compreensão da sociedade em suas causas e efeitos. Apesar dessa "contribuição externa" ser significativa para o campo do direito, Weber estava mais concentrado na questão da legitimidade da autoridade do que especificadamente na legitimidade sob o viés jurídico. ${ }^{15}$

Weyma Lübbe aplicou as categorias de Max Weber sobre a questão da legitimidade às sistematizações teóricas de três autores: Hans Kelsen, Jürgen Habermas e Niklas Luhmann, buscando avaliar em que medida a legitimidade fortalece a legalidade. Sobre essa contribuição, importa aqui que, para Lübbe, legitimidade possui no plano jurídico uma relação decisiva com o conceito de validade. Validade de uma ordem no sentido jurídico seria a capacidade da validade de fortalecer as normas positivas. No sentido sociológico a validade fortalece a influência sobre as atividades sociais e, no sentido filosófico, a validade fortalece a fundamentação ou o fundamento de justificação. Contudo, a dogmática jurídica, a filosofia jurídica e moral e a sociologia jurídica se influenciam, definem e mutuamente se corrigem, e é difícil dissociar completamente o papel da legitimidade em relação à legalidade sem fazer referência a esses campos de forma conjunta, já que o conceito de validade jurídica é, nesse contexto, angular. ${ }^{16}$

Apesar de Thomas Franck não ter adotado, em seu livro, o termo percepção com destaque - o que pode significar uma revisão teórica - é difícil desvincular legitimidade do contexto das percepções de atores sociais. Normas são tidas como legítimas porque são dessa forma percebidas por atores sociais. Dentre os diversos autores que pesquisaram esse tema é sempre memorável a contribuição de Robert Jervis que afirma que a visão que temos do mundo é mais psico-lógica do que lógica, porque incluímos diferentes critérios de validação da realidade, diferentes critérios de consistência cognitiva para a interação entre dados e teoria. ${ }^{17}$ Por que o mesmo não ocorreria com as normas de direito internacional?

Por outro lado, dizer que a legitimidade é uma propriedade da norma é afirmar que, independentemente das percepções sociais, uma norma por si só reúne elementos de legitimidade. A despeito da mudança no conceito, o modelo teórico proposto por Franck possui estas duas dimensões: a percepção de atores e a propriedade da norma. De qualquer forma, mesmo que a norma possua propriedades por si só, estas só podem ser assim qualificadas a partir da apreensão cognitiva por atores sociais.

A segunda parte da definição de 1988 remete às fontes de direito válidas. Mas o que são fontes de direito válidas no direito internacional? Essa pergunta é tradicionalmente respondida pelo artigo 38 do Estatuto da Haia, o qual menciona, em linhas gerais, os tratados, o costume, como prática geral aceita como sendo direito, e os princípios gerais do direito. Contudo, esse é um tema controverso na teoria e na prática internacionalista, que na opinião de Nicolas Onuf assume as seguintes nuances: 
The sources of International Law are not as they seem. This judgment follows reasonably enough from the realization that International Law is not the single, homogeneous thing it is usually thought to be. We observe, however, that while legal minds differ greatly on essential properties of law, the more so when they consider international law, sources are invariably presented in the same, uniform way. How can sources doctrine have persisted, so little challenged or changed, for centuries? 18

A questão levantada por Onuf tem relação direta com a questão da legitimidade. O entendimento específico acerca de um sistema legal possui consequências diretas para a validade ou legitimidade de normas. Segundo Hans Kelsen, por exemplo, para uma norma ser considerada válida, ela deve estar de acordo com uma norma superior também válida. Sobre esse assunto, se não há consenso entre juristas internacionalistas sobre as fontes normativas no plano internacional, como poderia haver - ainda no plano teórico - consenso sobre a validade de normas e decisões judiciais e administrativas? A legitimidade de uma norma passa pela percepção de que ela foi criada a partir de fontes válidas, caso esse sistematizado por Franck como validação simbólica ou ritualidade. ${ }^{19}$ Se não há consenso sobre as fontes válidas, não há consenso sobre a legitimidade da norma. É o que Onuf traduz como "persistência por parte da doutrina”.

Mesmo que fontes não convencionais - no duplo sentido, não tradicionais e também não previstas em convenções internacionais - , fossem admitidas pelas teorias onde é natural que sempre se encontrem posições dissonantes -, o fator legitimidade de alguma forma persistiria, pois a questão da legitimidade de normas não se reduz à questão do pertencimento às fontes válidas.

Quando o tema é legitimidade, os enfoques dados por filósofos, politólogos e juristas, são diferentes. No campo jurídico, teorias possuem alcance ilimitado, podem avançar indeterminadamente, mas o jurista ou o político necessita decidir, precisa de uma resposta única, que pode ser encontrada nos discursos teóricos. Em última análise, a decisão pode ser tida como o elemento mais importante da prática jurídica. $\mathrm{Na}$ teoria, o direito não tem fronteiras, pois o campo teórico é rico em ideias alternativas. No campo prático, as alternativas limitam e moldam a decisão ao que a decisão encerra com as alternativas.

Os últimos elementos mencionados na primeira definição proposta por Franck apontam para fatores sociológicos, antropológicos e filosóficos. No final da definição, ele resgata a questão dos elementos do devido processo de formulação da norma, os quais são identificados como decisivos para o gradiente da percepção de legitimidade em normas. À primeira vista, o autor incorpora diferentes ópticas sobre a matéria: a problematização das fontes de direito; os fatores diversos ligados às concepções culturais, políticas e societárias; e, por fim, a questão da legitimidade pelo procedimento. 
Um dos fatores para o cumprimento da norma é sua fonte, a qual pode indicar a maior probabilidade de ela ser cumprida. Esse fator, nos termos de Franck é denominado "pedigree", que não é o único indicador sobre a geração de comportamento estatal em conformidade com o conteúdo normativo.

O termo pedigree não é novo na linguagem jurídica. Para explicar o termo é oportuno estabelecer uma diferença teórica entre o positivismo de Hans Kelsen e o de Hart que ensejou a incorporação do termo pedigree na literatura jurídica. Colocando os dois autores em perspectiva, Alexander Somek explica que Hans Kelsen estava interessado nas condições de validade da norma jurídica e não na interconexão entre convenções com pedigrees variáveis. ${ }^{20}$ Herbert Hart concentra-se na questão de critérios de reconhecimento da norma, mais do que critérios de validade. Em Hart, a questão da validade é resolvida a partir da teorização da regra de reconhecimento a qual permite que pessoas na esfera pública e privada sejam providas com um critério de autoridade para a identificação de regras primárias obrigatórias. Regras primárias são as diversas regras nos mais diferentes níveis que existem na sociedade e a regra secundária é aquela que é anuída em termos de sociedade política para identificar quais regras são válidas como obrigatórias ${ }^{21}$. Dworkin utilizou o termo pedigree para caracterizar os critérios proporcionados pela regra de reconhecimento de Hart. ${ }^{22}$ Tanto em Dworkin como em Franck pedigree se refere à maneira pela qual regras são adotadas ou criadas pelas instituições jurídicas:

O direito de uma comunidade é um conjunto de regras especiais utilizado direta ou indiretamente pela comunidade com o propósito de determinar qual comportamento será punido ou coagido pelo poder público. Essas regras especiais podem ser identificadas e distinguidas com o auxílio de critérios específicos, de testes que não tem a ver com seu conteúdo, mas com o seu pedigree ou maneira pela qual foram adotadas ou formuladas. Estes testes de pedigree podem ser usados para distinguir regras jurídicas válidas de regras jurídicas espúrias (...) e também de outros tipos de regras sociais que a comunidade segue, mas não faz cumprir através do poder público. ${ }^{23}$

Nessa transcrição, o termo foi utilizado no contexto da crítica à teoria legal de Hart. É, por sua vez, utilizado por Thomas Franck para determinar a fonte de cada regra, ${ }^{24}$ mas também pode ser utilizado no contexto da percepção da propriedade, do gradiente de legitimidade que uma norma possui em função de sua fonte.

A crítica de Dworkin à Hart acrescenta que o pedigree não levaria em conta o conteúdo da norma. Neil Mccormic, por exemplo, especifica a crítica destrutiva de Dworkin sobre Hart destacando que os princípios legais - e também a opinião do judiciário - não são passíveis de identificação por pedigree através de uma norma de reconhecimento. ${ }^{25} \mathrm{O}$ conteúdo moral da norma, a saber, se é justa ou não, não faz 
parte dos critérios da regra de reconhecimento, crítica esta veementemente refutada por Hart. 26

Thomas Franck também formulará perguntas sobre a moralidade da norma como um fator que influenciaria na percepção de legitimidade e a resposta o aproxima do positivismo jurídico. Para ele, os conceitos de justiça e legitimidade são distintos e não constituem variável dependente um do outro. ${ }^{27}$ Ao final deste artigo o tema da justiça e da moral serão retomados.

Outra pergunta colocada por Franck é por que estudar o sentido teleológico das leis, para que existem leis e quais as causas de obediência? ${ }^{28}$ Questões que manifestam o interesse na obrigação legal e que mantêm o foco nas condições para a aceitação política e sociológica da lei. Não apenas por supostamente participar da Manhattan School, um grupo de pensadores da Universidade de Nova York com interesses e métodos comuns, mas também devido ao estudo das normas internacionais a partir da observação do comportamento de atores que Franck é considerado um continuador da obra de Luis Henkin. ${ }^{29}$

Para Franck, a questão da legitimidade parte do questionamento austiniano acerca da natureza do direito internacional. ${ }^{30}$ Ele compreende que algumas regras são mais persuasivas do que outras no sentido da atratividade para o cumprimento, o que pode ser observado também no plano nacional e subnacional. Esse tipo de observação acerca da dinâmica de normas propicia a diferenciação entre coerção e legitimidade, ou seja, entre os diferentes papéis da coerção e da legitimidade no que diz respeito à relação entre sistema legal e obediência dos atores aos quais as normas jurídicas são destinadas.

O estudo da legitimidade em sistemas legais nacionais como um fator não coercitivo que conduz à obediência pode iludir o pesquisador em virtude de a legitimidade poder ser confundida com o elemento que compele à obediência: a autoridade.. Essa possível confusão arrefece no domínio do direito/sociedade internacional. Apesar de na sociedade internacional existirem unidades administrativas dotadas de notável autoridade, não existe uma autoridade política central na mesma proporção do Estado no que diz respeito aos Estados nacionais. Contudo, existem elementos que compelem sujeitos de direito internacional em direção ao cumprimento de normas, ainda que a não obediência a estas ofereça vantagem comparativa.

\section{Propriedades da nORMA: PerCePÇÃo de PEDIGREE}

O esforço descritivo de Franck em relação à legitimidade de normas internacionais é marcado pela observação do comportamento da sociedade internacional. Por isso a afirmação, presuposta, de que muitas regras são obedecidas na maior parte do tempo 31 ou sobre o desconforto que a desobediência a regras pode causar no violador. ${ }^{32}$ Esses tipos de percepção parecem ser resultantes da ênfase sociológica dada ao estudo, pois o método desta pesquisa concentra-se no comportamento de Estados. 
A aproximação "sociológico-comportamental” presente nas opções metodológicas da Escola de Manhattan enfatiza a relação entre o cumprimennto de regras internacionais e comportamento de Estados - mas também o raciocínio que a adequação de Estados à exigência da norma é mais frequente do que a mera coicidência ou fortuitividade poderiam sugerir. A seguinte passagem de Louis Henkin reflete esse viés:

One frequently encounters the view that international law is made by the powerful few to support their particular interests. Paradoxically, it is a common view also that the norms of international law are so widely disregarded as to be largely irrelevant to the behavior of nations. Some have even elevated this impression to a doctrine, questioning whether one may meaningfully speak of international norms, of their observance or violation. When nations do behave consistently with law, it is commonly seen as fortuitous: the law happened to coincide with what nations wished to do. But this coincidence is too frequent to be mere coincidence. ${ }^{33}$

A ideia de Henkin possibilita visualizar por que Kennedy considera que o "The Power of Legitimacy" é em muitos sentidos a extensão de "How Nations Behave?": o interesse na obrigação legal e o foco nas condições políticas e sociológicas da aceitação da lei. ${ }^{34}$ Se Estados cumprem normas mesmo frente à inexistência de um poder coercitivo e, algumas vezes, mesmo se contrárias aos seus interesses; quais fatores confeririam a determinadas normas a capacidade de maior atratividade em direção ao cumprimento? Esta pergunta é respondida por Thomas Franck no sentido de que a legitimidade de normas internacionais, ou para a criação de normas internacionais, existe em função de percepções no plano internacional acerca das mesmas. Essas percepções dizem respeito a quatro elementos: determinação, validação simbólica, coerência e aderência. Estes fatores são critérios relativos à percepção de legitimidade de normas jurídicas internacionais.

\section{I DETERMINAÇÃo}

Determinação de uma regra é a habilidade do texto de possuir uma mensagem clara, de ser transparente a ponto de se poder chegar ao significado através da linguagem. A lógica do raciocínio é que regras com um significado claro e inequívoco são compreendidas de forma mais eficiente e possuem maior potencial de serem cumpridas já que expressam com maior precisão o comportamento que se espera dos destinatários. Indeterminação, por outro lado, não é somente a característica de não comunicar inequivocamente o comportamento exigido pela norma, como também, torna o não cumprimento mais fácil de ser justificado. ${ }^{35}$ Franck propõe que excelentes exemplos do custo da indeterminação são casos das regras, aprovadas em 1974 na Assembleia Geral das Nações Unidas, ${ }^{36}$ que definem e proibem a agressão. No prefácio de J. H. H. Weiler 
para a edição do European Journal of International Law dedicada à interpretação de tratados, destacam-se três fatores para o re-exame das questões interpretativas as quais podem ser relacionadas com o que Franck denomina determinação: a fragmentação do direito internacional que sugere distintas linguagens e idiomas hermenêuticos; a crescente especialização de tribunais internacionais com diferentes vocabulários hermenêuticos; e a relação no plano teórico entre direito e relações internacionais com certo impacto sobre a interpretação de tratados. ${ }^{37}$ Esses fatores hermenêuticos podem ser reconhecidos como agregadores de legitimidade de normas internacionais na medida em que reforçam a determinação (convergências interpretativas) de normas internacionais e não se confundem com o interpretativismo referente às reflexões de Ronald Dworkin que, segundo Basak Çali, foi recebido com indiferença pelos teóricos do direito internacional. 38

A título de menção, dentre os esforços da pesquisa brasileira destaca-se o trabalho de George Galindo sobre a noção de patrimônio comum da humanidade da Convenção de Montego Bay - em boa medida inspirado nos "critical legal studies" - no qual ele enfatiza questões interpretativas no contexto do regime para o uso dos oceanos. Ao trabalhar a "pacífica" transformação da noção de patrimônio comum da humanidade como consagrada na Convenção das Nações Unidas para o Direito do Mar, esse autor evidencia o quanto conceitos passíveis de interpretações diversas - como universal são modelados segundo contextos políticos, culturais e históricos. ${ }^{39}$

A indeterminação de uma norma internacional gera o desacordo entre as partes envolvidas quanto ao conteúdo do comando. Outro exemplo é a Resolução 242, do Conselho de Segurança das Nações Unidas, de 22 de novembro de 1967. A disputa semântica, em particular sobre a cláusula operativa 1(i), também em função da falta de congruência entre a versão inglesa e a francesa geraram interpretações que ainda questionam o conteúdo da decisão. ${ }^{40} \mathrm{~A}$ decisão política, com validade no campo normativo, que determinou a retirada israelense dos territórios ocupados na Guerra dos Seis Dias persevera até hoje. Talvez, nesse caso, a indeterminação possa ser utilizada e compreendida como estratégia política. Quanto maior é a controvérsia no plano político, maior será a probabilidade de alegação de indeterminação e não de indeterminação em si. É observável, nesse caso, que a determinação possa ser característica resultante tanto da imprecisão ou descuido quanto ao conteúdo semântico da norma quanto dos interesses em disputa no processo político que a cria.

Tendo que legitimidade é a propriedade da regra de atrair os destinatários desta em direção ao cumprimento, o grau de determinação da norma afeta o grau de percepção de sua legitimidade. É o que Franck denomina de transparência como um dos sentidos da determinação. Estados evitam descumprir normas em curto prazo porque podem visualizar situações futuras nas quais a regra lhes favorece. O não descumprimento da regra fortalece a transparência da regra e gera maior possibilidade de previsão e expectativas acerca do comportamento futuro da sociedade internacional. ${ }^{41}$ 
Para Franck, as expectativas de reciprocidade operam como constrangimentos no sistema internacional, mas para que essa característica vigore são importantes os entendimentos mútuos sobre o alcance da norma. ${ }^{42}$ Para explicar o papel do cumprimento dessas expectativas, Franck recorre à relação entre direito diplomático e opinião pública, no caso da aplicação (ou não) das imunidades previstas na Convenção de Viena de 1961. A imunidade diplomática, em alguns casos de crimes que chocam a opinião pública, não é suficiente para Estados não manterem os privilégios. Estados cumprem a garantia de imunidade diplomática em seu território porque possuem interesse na proteção de seus acreditados.

O direito diplomático é um dos exemplos mais claros de um corpo de direitos positivados a partir de práticas costumeiras em nível internacional. Logo, o cumprimento das normas internacionais que regem as relações diplomáticas pode não obedecer somente ao sistema de expectativas de reciprocidade, mas também a outros fatores: práticas reforçadas pela construção histórica que permitem a formação do costume que modela o comportamento dos atores internacionais em termos de valores e padrões societários entendidos como exigíveis (opinio juris) e, consequentemente, com maior densidade de consenso político.

Certas características das imunidades diplomáticas - também como resultado da opinião pública - têm sido rediscutidas. ${ }^{43}$ Aqui, opinião pública é entendida como moldada por órgãos de políticas nacionais ou corporativas e não como uma "consciência aberta do mundo" conforme algumas posturas, talvez equivocadas, do entre guerras, descritas por Morguenthau. ${ }^{44}$ A rediscussão permite entender que mesmo normas com elevado grau de obediência - opinião de Thomas Franck sobre a Convenção de Viena de 1961 -, são questionadas quanto à legitimidade. Os processos de aprimoramento do sistema normativo podem reforçar a legitimidade da norma na medida em que o consenso obtém amplo alcance político por parte dos negociadores. Nesse caso, a legitimidade possui um caráter dinâmico: normas são legitimadas continuamente mediante processos políticos.

O sentido que Franck atribui à transparência das regras internacionais é tanto o de um comando claro, inequívoco quanto à antecipação de uma situação futura em função de regra específica para determinado Estado ou grupo de Estados. Nesse último sentido, cumprir momentaneamente uma norma contrária aos seus interesses reforça o sentido do comando normativo e da necessidade deste ser obedecido sistemicamente na comunidade internacional. Muito embora Franck argumente que as regras internacionais sobre a atividade diplomática detenham um alto grau de especificidade esse fato não pode ser compreendido como fator preponderante de atração para o cumprimento em nível sistêmico.

A indeterminação de normas internacionais pode ser compreendida como parte da indeterminação da própria sintaxe jurídica. Na obra The Decay of International Law, de 1986, Anthony Carty debate a questão do discurso racional legal e chega a afirmar 
que se deve reconhecer que um aparente positivismo jurídico objetivo é constituído pela recusa à necessidade do argumento racional de qualquer tipo:

Yet the resort to a so-called Grundnorm, for instance the principle of pacta sunt servanda (that treaties must kept) as the point beyond which lawyers need not go, is in fact nothing more than the point beyond which they do not care to go. In fact international lawyers do not have to satisfy standards of rationality higher than for any other type of discourse. For instance the right to demand an explanation can always be countered by a request for an account of what is unclear. Arguments may frequently be regressive and hence incapable of complete justification. Yet this stage is not reached until one has identified what premises of argument are not recognized as valid. In my view international lawyers are not clear about the assumptions which have become encrusted on to their discipline, and so they are in no position to say that beyond their legal method lays an abyss, the dreaded legal vacuum. ${ }^{45}$

As considerações de Carty propõem um novo ângulo de análise para a questão da legitimidade de normas internacionais, que pode complementar o raciocínio de Franck. Se, para este, determinação é uma qualidade da norma e fator que exerce atração em direção ao seu cumprimento, então, existem dois elementos para o cumprimento da norma: a norma em si e as qualidades da norma que lhe conferem legitimidade. A crítica de Carty sustenta que há uma indeterminação em relação ao próprio recurso à justificação de normas, muito embora o que Carty compreenda por racionalidade do argumento jurídico não seja o mesmo que Franck entende por determinação da norma. A indeterminação a que Carty faz referência é que os argumentos que sustentam a prática jurídica recorrem a conceitos imprecisos, destituídos de conteúdo claro. Por outro lado, não existe sistema social e jurídico que não recorra a pressupostos resultantes de processos emocionais e mentais e, por isso, (por que não reconhecer?) vácuo legal. Em certa medida, o que Carty entende por abismo, vácuo legal, Gunter Teubner descreve como autorreferencialidade do sistema legal que finaliza a performance de deter os paradoxos e liberar a dinâmica jurídica. ${ }^{46}$

Ainda, sobre "determinação", Thomas Franck reconhece que regras vagas podem aumentar a margem de decisão acerca de determinado direito. Uma regra não binária, lícito/não lícito, permite a maior amplitude da decisão acerca de determinada previsão normativa ${ }^{47}$. A esse respeito cita o artigo 83, 1, da Convenção das Nações Unidas para o Direito do Mar, o qual procura solucionar os direitos sobre a plataforma continental de países vizinhos, sugerindo que a plataforma deva ser particionada "in order to achieve an equitable solution". "Equitabe solution" é um conceito indeterminado que dá margem às mais diversas retóricas no plano político e jurídico.

O sistema jurídico internacional é composto de normas e princípios aos quais aplica-se reiterado exercício hermenêutico. A esse respeito, o jus cogens, no contexto 
da dogmática do direito internacional público, é um exemplo de regra não binária que adquiriu significado a partir de decisões jurídicas. Apesar de o jus cogens ser mais antigo que o próprio direito internacional contemporâneo, a inclusão desse instrumento de hierarquização de normas internacionais encontrou inicialmente cepticismo para sua inclusão nos artigos 53 e 64 da Convenção de Viena para o Direito dos Tratados, de 1969. ${ }^{48}$ O problema do jus cogens é que não existe uma maneira objetiva de resolver casos de conflitos entre normas não derrogáveis em abstrato. Comentadores convergem no fato de que não existe uma lista de normas jus cogens porque a própria formulação normativa ("accepted and recognized by the international community of States as a whole”, art. 53 da Convenção de Viena sobre o Direito dos Tratados de 1969) não é imune às controvérsias.

Com o passar dos anos, o enfrentamento de questões concretas por instâncias decisórias, principalmente no campo jurisprudencial - das quais uma das mais conhecidas foi o caso Pinochet - contribuiu para a noção de que normas acerca da proibição de agressão, escravidão, genocídio, discriminação racial, tortura, assim como normas de direito humanitário em situações de conflito e direito à autodeterminação são normas jus cogens. Manifestações da Comissão de Direito Internacional incluem ainda a pirataria, o tráfico de pessoas e o uso ilegal da força, o que reforça a ideia de que o jus cogens afirma-se pela decisão e pelos escritos de direito internacional em diferentes planos institucionais e também em diferentes casos e épocas. ${ }^{49}$ Esses são casos de normas que possuem aumento de legitimidade na proporção do aumento da determinação. Na medida em que as decisões sobre casos concretos delimitam o alcance e o significado da norma esta torna-se mais determinada. Ao mesmo tempo, essas decisões devem ser amplamente consensuais em virtude do próprio registro normativo ("accepted and recognized by the international community of States as a whole"). ${ }^{50} \mathrm{~A}$ propósito, as instâncias que decidem pela materialização do direito também estão inseridas no contexto do grau de legitimidade:

In practice, the legitimacy of a forum can be tested in the same way as that of a rule: by reference to the determinacy of its charter, its pedigree, the coherence of its mandate and its adherence to the normative institutional hierarchy of international organization. Nowadays, the UN General Assembly and Security Council, as well as organs of regional organizations, sometimes play this clarifying role. ${ }^{51}$

Regras vagas perdem em “determinação”, não obstante possam exigir de instâncias decisórias o entendimento padronizado do que seja o conteúdo da norma não binária. Com as considerações sobre a participação das instâncias decisórias num sistema de reconhecimento de grau de legitimidade encerram-se as considerações sobre "determinação". 
Nos anos 1980 ficou registrado um ensaio acerca do debate sobre determinação de normas internacionais. A pluralidade e a fragmentação de metodologias levaram o direito internacional para o campo da análise econômica e social e também para o domínio da linguística. Para Franck, num tom desanimador, a lei rapidamente se tornou tudo ou nada. Em um comentário a respeito de um tratado escrito por Schachter, Franck registrou que a força de uma obra é justamente modular e incorporar contradições não somente no campo dos imperativos irreconciliáveis, mas também entre as abordagens cognitivas. Sobre esse debate, David Kennedy, paradoxalmente, opinou que as alternativas retóricas retiraram muito da determinação do direito internacional e que, embora os balanços tenham gerado acomodações de uma retórica em relação à outra - elas podem gerar um sentimento de determinação. A indeterminação do direito internacional parece ser o segredo do seu sucesso. ${ }^{52}$

\subsection{VALIDAÇÃo SIMBÓliCA, PEDIGREE E RITUAL}

A validação simbólica é a segunda propriedade capaz de conferir percepção de legitimidade às regras internacionais e relaciona-se, mas não identifica-se, com as propriedade de pedigree e de ritual. A validação simbólica, o pedigree e o ritual possuem a característica de ser a dimensão cultural e antropológica da legitimidade, enquanto a determinação é a linguística e semiótica. A validação simbólica "occurs when a signal is used as a cue to elicit compliance with a command. The cue serves as a surrogate for enunciated reasons for such obedience". 53

O ritual é uma forma especializada de validação simbólica marcada por cerimônias que lançam mão de razões não enunciadas que suscitam a observância de comandos de pessoas ou instituições. Todo o ritual é uma forma de validação simbólica embora o inverso não seja necessariamente verdade. Franck exemplifica a validação simbólica sugerindo as cerimônias de reconhecimento, como quando as Nações Unidas admitem um novo Estado-membro, cerimônia que o dota de direitos e deveres. Nesse contexto, estaria Carl Schmidt certo quando afirmou que todos os conceitos expressivos na moderna teoria do estado são secularizações de conceitos teológicos? ${ }^{54}$ A ritualidade das cerimônias dos chefes de Estado, os juramentos com símbolos religiosos, os gestos frente aos símbolos nacionais, os protocolos diplomáticos, etc, remetem à força da liturgia secular contemporânea no reforço de crenças contemporâneas por meio de sinais, gestos, símbolos, paramentos e atitudes não verbais. ${ }^{55}$

Ainda sobre validação simbólica, a versão de 1988 propõe uma série de exemplos relativos à sociedade asteca, china imperial, liturgia cristã, práticas parlamentares britânicas, para concluir que o pedigree é uma forma particularmente universal de validação simbólica. Citando exemplos diversos no campo da antropologia cultural, e mesmo das práticas aristocráticas, Franck argumenta que conexões de validação não são uma invenção moderna ou ocidental e que a maioria das sociedades faz alguma 
conexão linguística entre os conceitos “antigo" e "venerável”. ${ }^{56}$. Observa-se que os exemplos no campo da antropologia cultural, de sociedades pré-modernas bem como práticas societárias no interior das nações, não permitem argumentar em favor da existência da validação simbólica como propriedade da norma.

Quando Franck sugere exemplos relacionados com a prática do direito internacional contemporâneo - que efetivamente é o que ele se propõe a discutir - como uma convenção amplamente ratificada ou uma decisão unânime da Corte Internacional de Justiça, esse autor aponta fatores importantes da percepção de atores internacionais. ${ }^{57}$ É defensável que uma decisão unânime possa parecer mais legítima e, também, é perceptível que esse é um fator não jurídico - no sentido de não previsto pela norma internacional -, de atração em direção à obrigatoriedade da norma. Também é defensável que normas com maior número de ratificações tendem a expressar mais amplamente a noção de obrigatoriedade.

A observação sobre o argumento de Franck é que este não apresenta evidências se a validação simbólica - no sentido de instituições veneráveis ou de antiga tradição - constitui o fator que confere musculatura às decisões unânimes e às normas universalmente anuídas. A “égide de um venerável patrocinador”, conforme Franck denomina os casos de decisões unânimes e de tratados amplamente aceitos, diz respeito à percepção de que esses fenômenos supostamente indicam elevado consenso político. No plano da percepção, decisões e negociações consensuais são dados que oferecem consistência cognitiva para reconhecer que existe maior probabilidade de resultados jurídicos efetivos e, por isso, nos termos aqui utilizados, de maior legitimidade.

Segundo Franck, a prática diplomática está revestida de diversos elementos de validação simbólica: os títulos de embaixador plenipotenciário, as prerrogativas e imunidades dos embaixadores, cônsules, etc., estão entre os mais antigos símbolos e ritos na condução das relações internacionais, tendo em vista que o procedimento de acreditar representantes diplomáticos lhes confere pedigree ${ }^{58}$ Os juramentos de chefes de Estado e a manutenção de um sistema de bandeiras, hinos, brasões e condecorações são outros exemplos de validação ritual com liturgias rígidas que interferem na percepção de normas internacionais. A esse respeito, os atos unilaterais de Estados como o reconhecimento, a promessa, a denúncia, a renúncia -, revestidos de sua devida ritualidade, são fontes de direito reconhecidos pela doutrina. Apesar do princípio da igualdade jurídica de Estados, é possível perceber que na prática do direito internacional, os atos unilaterais são percebidos de diferentes formas no que diz respeito ao gradiente de legitimidade.

Exemplos significativos são dados pelos reconhecimentos de Estado: embora, em regra, não se discuta os pressupostos de existência e a validade dessa fonte normativa, a percepção do grau de legitimidade pode depender do momento político, da forma ritual, do prestígio e do interesse de quem os exerce. 


\subsection{Coerência}

Determinação e validação simbólica estão conectadas com a terceira variável: coerência, a qual, para Thomas Franck, possui dois sentidos. Primeiro, regras são coerentes quando casos parecidos são tratados de forma parecida quanto à aplicação da norma. Segundo, quando uma norma possui sentido em relação a outras normas num dado sistema normativo. Na primeira noção, Franck remete ao conceito de integridade de Ronad Dworkin. ${ }^{59}$ O segundo sentido de coerência - mais bem explorado pelo autor - dá-se quando uma regra, um modelo ou uma validação ritual reúne força, se é vista como conectada a uma rede de outras regras por um princípio norteador. A esse respeito, nas palavras de Marie Theres Fögen, uma lei raramente aparece só, pois a norma desnuda, assim parece, não existe; o que faz com que o brocardo "lei é lei" torne-se sem valor, ao que "lei não é lei" também não esteja certo. 60

A contribuição de Fögen, A canção da lei" (Das Lied vom Gesetz), reflete sobre os pressupostos de validade e legitimidade de normas numa dimensão que pode ser compreendida em termos da história da estética dos sistemas jurídicos, na medida em que coerência e consistência de normas possuem diferentes acepções nos termos da correta razão de construção -, no sentido latino de estética como recta ratio factibilium - de dado sistema de normas.

Para exemplificar a terceira propriedade da norma, Franck sugere um exemplo simples. Imagine-se a situação hipotética de uma instituição financeira internacional resolver perdoar a dívida de países do "Terceiro Mundo" num limite de até um bilhão de dólares para os que honrassem com o pagamento de metade do valor devido. $\mathrm{O}$ fato de haver um limite total do montante a ser "perdoado", acordado entre os países concedentes e os beneficiários dos empréstimos, faz com que apenas um grupo de países possa receber o benefício. Como implementar o acordado? Uma solução possível seria estipular uma ordem no pagamento dos créditos pelo critério alfabético (somente os Estados de A a N serão beneficiários). A possível decisão tem determinação, mas perde legitimidade porque carece de nexo lógico e prático. Dificilmente alguma questão no direito internacional seria resolvida pelo critério alfabético. A coerência é uma característica que aproxima a decisão do propósito da agência ou da norma. Assim, seria mais "coerente" conceder o "perdão de dívidas" a partir de critérios como produto interno bruto ou renda per capita.

Franck propõe três exemplos de que a coerência é uma chave indicadora de legitimidade: a emergência da autodeterminação, o desenvolvimento da noção de igualdade jurídica entre Estados, e o princípio do General Agreement on Tarifs and Trade acerca da nação mais favorecida.

Sobre o primeiro exemplo, ele esclarece que uma norma possui legitimidade o quanto mais próxima possível está de seu propósito. O termo autodeterminação surge ao término da Primeira Guerra Mundial, para se conseguir lidar com a 
questão das minoras étnicas na Europa do pós-guerra. Franck rgumenta que a perda de legitimidade da norma é perceptível gradualmente, em particular nas diferentes posições assumidas quanto à independência de Biafra e Argélia e, em geral, nas independências africanas.

De fato, Jean- Michel Veranneman destaca o que pode ser compreendido como uma causa eficiente para a problematização do termo jurídico "autodeterminação”: a guerra fria deu aos africanos a URSS e a China como aliados os quais declaravam-se a favor da emancipação dos povos e, por isso, movimentos independentistas contaram com o apoio de países comunistas e, depois, de países recentemente emancipados, conforme o caso da Argélia. ${ }^{61} \mathrm{~A}$ independência de Biafra por sua vez foi uma temporária e fracassada tentativa de secessão na Nigéria, reconhecida timidamente por quatro países africanos e pelo Haiti. Esse último caso, uma disputa controversa que oscila, em tese, entre a autodeterminação da etnia ibo e disputas entre companhias de petróleo anglo-americana e francesa. ${ }^{62}$ Os exemplos reforçam a ideia da coerência relacionada ao sistema de significados culturais e políticos compartilhados pelos atores prevalentes em dada sociedade na qual determinadas normas e princípios atuam.

O segundo exemplo diz respeito à adequação entre normas, princípios e valores da comunidade na qual Estados estão inseridos. A partir do momento em que um Estado é reconhecido pela comunidade internacional gera-se a noção de pertencer a uma comunidade com regras. Nesse tópico Franck acentua a questão do pertencimento à comunidade, mas também faz referência à ilegitimidade do poder de veto no Conselho de Segurança, e argumenta que a norma que confere suporte aos membros permanentes diz respeito ao mundo em 1945, quando havia uma clareza da responsabilidade das grandes potências, mas hoje esse panorama político está mudado. O juízo de Franck pode ser ponderado nos termos de que talvez não houvesse clareza quanto à responsabilidade das grandes potências, conforme o registro nos comentários de Hans Kelsen à carta de São Francisco em que, além de destacar que o poder de veto fora muito discutido, ele firma uma posição quanto à incompatibilidade com o princípio da igualdade jurídica entre Estados. ${ }^{63}$

O último exemplo diz respeito ao princípio da nação mais favorecida criado pelo General Agreement on Tarifs and Trade, que a princípio foi uma tentativa de intensificar o comércio e trazer benefícios a todos os Estados partes. Contudo, na prática, o princípio não estava favorecendo países pouco desenvolvidos e então foi criado um sistema de preferências que permite o acesso preferencial temporário de determinados países menos desenvolvidos. O sistema de preferências adequou a razão do princípio da nação mais favorecida que estava perdendo coerência no sistema de comércio mundial.

A coerência é característica ligada ao pertencimento a uma comunidade. Essa caraterística parte do pressuposto de que a observação da sociedade internacional indica que Estados não fazem interações aleatórias, mas aceitam responsabilidades derivadas 
em um comprometimento mais geral que é a de ser membro de uma comunidade. ${ }^{64}$ É claro que essa assunção também incorpora uma crença comum nas teorizações sobre as relações internacionais: a do Estado como um agente que decide racionalmente e age conforme um sistema de preferências a partir de vantagens comparativas. O tipo de caraterização que Franck faz da coerência é semelhante à que Oppenheim faz da base do direito internacional, ou seja, da caracterização de que a obrigatoriedade de uma norma provém da consciência de pertencimento a uma comunidade. ${ }^{65} \mathrm{Em}$ virtude de relacionar regras com princípios gerais adotados em uma sociedade, a coerência é considerada um critério horizontal.

\subsection{ADERÊNCIA}

A última propriedade da norma que interfere na percepção de legitimidade por uma comunidade é a aderência a uma hierarquia normativa e à comunidade. Com efeito, é um critério vertical. Muito embora Franck faça referência ao termo hierarquia normativa em nenhum momento a teoria pura do direito de Hans Kelsen é mencionada no texto.

Para explicar aderência, Franck recorre à Hart e à regra de reconhecimento. Mas como aplicar a regra de reconhecimento em uma sociedade primitiva e descentralizada? Torna-se, assim, difícil estabelecer um paralelo entre a regra de reconhecimento de Hart à prática do direito internacional contemporâneo. A respeito destas perguntas Franck argumenta que embora persevere a caracterização da comunidade internacional como "primitiva"66 é possível encontrar elementos de sofisticação e mesmo identificar normas secundárias, como a Convenção de Viena para o Direito dos Tratados e a Carta de São Francisco.

A rule community operates in conformity not only with primary rules but also with secondary ones-rules about rules-which are generated by valid legislative and adjudicative institutions. Finally, a community accepts its ultimate secondary rules of recognition not consensually, but as an inherent concomitant of membership status. In the world of nations, each of these described conditions of a sophisticated community is observable today, even though imperfectly. 67

A fim de justificar a opção metodológica de adotar H. Hart para explicar aderência é necessário reconhecer que na sociedade internacional existem regras secundárias o que hipoteticamente confere sofisticação jurídica a essa comunidade. ${ }^{68}$ Esse tipo de "ponte" teórica é necessária para comparar a capacidade do Parlamento britânico, de tribunais ou da Constituição americana, de reconhecer normas no interior dos Estados com tratados e instituições que atuam em nível mundial. É fundamental compreender que a obrigação de honrar tratados provém mais da condição de sócio do que do consentimento específico. 


\section{CONSIDERAÇões FinAis, EM TORNO DE, “E POR QUE NÃO A JUSTIÇA?”}

Em síntese, Thomas Franck propõe quatro propriedades da norma capazes de atrair sujeitos de direito internacional em direção ao seu cumprimento: determinação, validação simbólica, coerência e aderência. Todas são características que aumentam a percepção e a caracterização das normas internacionais em termos de legitimidade. O esforço de Franck vale pela tentativa de falar em legitimidade na perspectiva normativa, em particular, no âmbito do direito internacional, como ordem descentralizada.

Não fica claro nas reflexões de Thomas Franck como os critérios de legitimidade podem funcionar como critérios de percepção, de legitimidade. Muito embora a descrição das propriedade seja clara, a forma como Estados ou outros sujeitos de direito internacional percebem as propriedades não é objeto de estudo de Franck. A esse respeito, o método da análise, centrado na norma, interessa-se em descrever as propriedades de legitimidade de uma norma de direito internacional e não a forma como essas propriedades são percebidas. A despeito das aventuras metodológicas de Tom Franck, persevera a inquietante pergunta, em que medida é possível pesquisar a percepção de normas por sujeitos de direito no âmbito do campo dos estudos jurídicos.

Quando fala de determinação da norma, esse autor quer demonstrar que a clareza, univocidade e percepção compartilhada do comando geram propensão ao cumprimento. A validação simbólica evoca elementos sociológicos e ritualísticos que criam a percepção de pedigree de regras. Pode-se dizer que tanto coerência quanto aderência dizem respeito à relação de pertencimento à sociedade internacional: coerência no sentido de adequação aos princípios, valores e propósitos da norma, e aderência num sentido quase luhmaniano, ${ }^{69}$ ou seja, do reconhecimento de regras a partir de um sistema jurídico próprio de reconhecimento de regras válidas, sejam decisões, sejam leis escritas ou mesmo princípios e valores.

Algumas considerações sobre a contribuição de Thomas Franck podem ainda ser registradas. No livro de 1990, ele acrescenta dois capítulos sobre temas sobre os quais não havia feito menção no artigo de 1988. Os temas são legitimidade e comunidade e legitimidade e justiça. As perguntas básicas feitas nesses capítulos são, respectivamente, a respeito do conceito de obrigatoriedade da norma como resultado de uma ordem social coercitiva, e se a justiça não pode ser considerada um elemento na legitimidade da norma internacional. Justiça, neste caso, fez referência a um conceito multifuncional que pode ser tido como valor teleológico, ideal transcendente ou mesmo como ideal otimizador de determinados sistemas jurídicos. De qualquer forma, após o estudo da legitimidade como propriedade da norma em torno de quatro critérios, a questão da justiça sugere a possibilidade de avaliação da legitimidade de normas de direito internacional público a partir de valores éticos, o que em larga medida remete aos direitos humanos, à justiça transicional e ao jus cogens, por exemplos. 
No capítulo entitulado "Why not Justice?", Thomas Franck aponta duas razões para a justiça não ser incluída entre os fatores que produzem legitimidade: um fator operacional e um fator teórico. Sobre o fator operacional ele aduz que a justiça só pode ser feita a pessoas e não a entidades coletivas. Assim, é possível dizer que o Tratado de Versailles fez uma injustiça com a Alemanha - como entidade coletiva no final da primeira Grande Guerra em relação ao que os alemães - como indivíduos - sofreram com inflação, desemprego e perdas sociais, consequências da imposição de reparações. O fator teórico, por sua vez, relaciona-se com distinção entre legitimidade e justiça. Muito embora haja relação sinérgica entre esses dois conceitos, e ambos tendam a atrair em direção à obediência não coercitiva, nenhum é variável dependente do outro. ${ }^{70}$

O tema da justiça, segundo as reflexões de Thomas Franck, remete aos postulados do positivismo jurídico de Hart e Kelsen, tão influenciadoras de sistemas jurídicos ocidentais. Hans Kelsen é enfático em reafirmar que justiça e injustiça não são qualidades inerentes à norma, mas qualidades do ato pelo qual ela é posta, do ato de que ela é o sentido. ${ }^{71}$ As proposições da teoria geral descritiva de Hart por sua vez afirmam que não há nenhuma conexão conceitual necessária entre o conteúdo do direito e o conteúdo da moral e, portanto, disposições perversas podem ser juridicamente válidas como regras ou princípios jurídicos. ${ }^{72}$ É nesse sentido que se pode sugerir que o trabalho de Franck é marcado por duas características do positivismo jurídico: a centralidade do debate na norma e a particular distinção entre norma jurídica e moral.

David Kennedy registra que Tom Franck, nos anos 1990, justamente quando publica seus estudos sobre legitimidade, deixou a justiça fora da história. O autor faz anedota do fato de que o Franck dos anos 1960 tinha enviuvado. Acrescenta que ser "rule-oriented" é uma característica da Escola de Manhattan assim como a sociologia universal do agir conforme o comando. ${ }^{73}$

Outra consideração de Franck em atenção ao tema da justiça é que existe a necessidade no sistema internacional de que o sistema legal seja de tal forma legitimado que exerça atração não coercitiva em direção ao seu cumprimento. A partir da observação da prática, do comportamento de atores em nível global, em termos de geração de comportamento, de obediência às normas de direito internacional público, existem pelo menos dois momentos distintos: o primeiro é a criação e o reconhecimento social de normas tidas como legítimas. A meta de assegurar a justiça nesse dado sistema de regras é de segunda e não a primeira ordem na agenda global. ${ }^{74}$ Essa afirmação reforça a centralidade da análise na norma e não na aplicação da norma pela autoridade.

O elemento justiça como propriedade que confere legitimidade à norma não é definitivamente um tópico unânime nos discursos teóricos legais contemporâneos. Com sua Teoria da justiça, de 1971, John Rawls defendeu a necessidade de demonstrar que é racional para os membros de uma sociedade bem ordenada afirmar seu 
senso de justiça como regulador de seu plano de vida. ${ }^{75} \mathrm{Na}$ tentativa de aprofundar sua teoria em termos de sociedade internacional, no seu Direito dos povos, de 2001, talvez com menor entusiasmo em termos de receptividade dentre seus pares, Rawls repete o recurso às concepções de justiça nos termos de uma razão pública. ${ }^{76} \mathrm{As}$ ideias de justiça nas relações jurídicas internacionais aparecem também na qualidade de exemplo de esforços destacados, em Jürgen Habermas, Martha Nussbaum, e em autores intelectualmente engajados com os temas relacionados aos direitos fundamentais em nível global.

Já nem o positivismo formalista de Hans Kelsen, nem o decisionismo de Carl Schmitt anuem com a tese da legitimidade da norma a partir do critério da justiça. Influenciado por Carl Schmitt, Hans Morgenthau, por exemplo, compartilha a visão de que a ética e a justiça não possuem relação com o direito internacional. ${ }^{77}$ Em sua última obra no campo da teoria legal, La réalité des normes. En particulier des normes du droit inernational (1934), Morgenthau, enfatizara o aspecto da validade de normas internacionais numa acepção diferente da de Kelsen: "for him, such validity was not, however, constituted by relations of systemic delegation (as in Kelsen but by the norm abstract ability to determine the content of someone's will)". ${ }^{78}$ É neste sentido que embora haja uma aproximação de Franck em relação ao positivismo jurídico é bem verdade que também outras correntes teóricas - ainda que de forma diversa - insistirão que a justiça não é propriedade da norma, mas faculdade dos atores, agentes, dos sujeitos de direito em criá-la e aplicá-la.

Sobre a questão da justiça e da universalidade dos direitos humanos Thomas Franck publicou o texto "Are Human Rights Universal?", em fevereiro de 2001, na Foreign Affairs, que auxilia na compreensão da localização do elemento moral na questão da legitimidade. Franck questiona a universalidade dos direitos humanos a partir da possibilidade da existência de diferentes sistemas de valores morais, o que ele denomina cultural exceptionalism, e argumenta que hoje existe um conflito entre um mundo imaginado, no qual cada pessoa é livre para desenvolver seu próprio potencial, e um outro no qual identidades e significados derivam segundo fatores imutáveis: genética, territorialidade e cultura. ${ }^{79}$

A dificuldade de coordenação entre a pretensão de normas universais e a heteronomia dos sistemas jurídicos no plano global parece ser tema de crescente interesse por parte de juristas, o que pode ser reconhecido como parcela dos esforços críticos sobre o conjunto teórico, normativo e ideológico relacionado aos direitos humanos. A esse respeito, as reflexões de Gunther Teubner sobre o pluralismo legal da sociedade global evidenciam que não é possível uma unidade legal em nível internacional, o que se traduz na dificuldade de hierarquização de normas no plano global pretendida pelo jus cogens ${ }^{80}$ e, por que não, pelos direitos humanos. Diversos textos de David W. Kennedy, um revisor dos textos de Franck, também expõem o equívoco de conceitos vinculados à justiça global e direitos humanos, como sociedade internacional, que 
para ele refere-se a uma elite que é audiência para a mídia global, ${ }^{81}$ assim como direitos humanos, e seria uma linguagem normativa comum para um grupo medir, denunciar e defender a legitimidade do poder político.

O texto "Are Human Rights Universal?" defende a ideia da prevalência dos direitos humanos sobre excepcionalidades culturais. A partir da retomada da história europeia, Franck argumenta que os padrões mínimos dos direitos não são uma tradição cultural ocidental conforme muitas vezes o direito internacional é visto. No texto não há referência à justiça ou à moral universal. Embora, para o autor, pareça mais apropriada a ideia de direitos humanos universais, ele entende que a legitimidade é fruto de processos culturais e específicos: batalhas de ideias poderosas, do tipo que sacodem os pilares da história. 82

: ARTIGO APROVAdo (01/06/2012) : RECEBIDO EM 17/05/2011

\section{NOTAS}

1 O professor Thomas M. Franck faleceu em 27 de maio de 2009. A título de breve referência, a New York University informa na página web, in memoriam, que: "Franck, a leader in the field of international law, joined the NYU School of Law faculty in 1960, and served as the director of the Center for International Studies from 1965 until his retirement in 2002. Under his leadership, the center trained hundreds of students in international law, hosted numerous distinguished fellows, and produced a large amount of influential research". Disponível em: http: / /law.nyu.edu/news/ FRANCK_IN_MEMORIAM. Acesso em: 19 nov. 2010.

2 Kennedy, 2003, p. 401.

3 Kennedy (2003, p. 413) afirma que essa obra é a síntese intelectual do que definiria o direito internacional nos EUA por mais de vinte anos.

4 Kennedy, 2003, p. 404.

5 Kennedy, 2003, p. 429 e 432.

6 Roberts, 2001, p. 757-791.

7 Franck, 1988, p. 705.

8 Fonseca Jr., 1998, p. 166.

9 A esse respeito: "Laws proper, or properly so called, are commands; laws which are not commands, are laws improper or improperly so called. Laws properly so called, with laws improperly so called, may be aptly divided into the four following kinds. 1. The divine laws, or the laws which are set by God to his human creatures. 2. Positive law: that is to say, 
laws which are simply and strictly so called, and which form the appropriate matter of general and particular jurisprudence. 3. Positive morality, rules of positive morality, or positive moral rules. 3. Laws methaphorical or figurative, or merely metaphorical or figurative. (...) "The so called law of nations consists of opinions or sentiments current among nations generally. It therefore is not law properly so called. But one supreme government may doubtless command another to forbear from kind of conduct which the law of nations condemns. And, tough it is fashioned on law which is law improperly so called, this command is a law in the proper signification of the term. Speaking precisely, the command is a rule of positive morality set by a determinate author. For, as no supreme government commanding does not command in its character of political superior. If the government receiving the command were in a state of subjection to the other, the command, though fashioned on the law of nations, would amount to a positive law" (Austin, , 1998. p. 1, 142).

10 Nesse caso Franck possui duas hipóteses, uma que é um pressuposto (cumprimento das normas internacionais) e a outra para qual deseja acrescentar evidências (que a legitimidade possui influência no processo de cumprimento de normas). Quanto aos denominados pressupostos de cumprimento, no artigo de 1988, lê-se: "The surprising thing about international law is that nations ever obey its strictures or carry out its mandates" (Franck, 1988). No texto do livro de 1990, Frank pouco altera seu pressuposto: "In the international system, rules usually are not enforced yet they are mostly obeyed" (Franck, 1988, p. 3).

11 Franck, 1988, p. 706.

12 Franck, 1990, p. 24.

13 Weber, Max. Economia e sociedade. 4. ed. Brasília: Editora Universidade de Brasília, 2004, p. 21.

14 Banshoff, 2004, p. 5

15 Já o início desse debate é interessante situar que se compartilha a visão que as contribuições sociológicas são "externas” já que o objeto estudado diz respeito ao direito internacional e, portanto, jurídico. (TEUBNER, Gunter. Selbstsubversive Gerechtigkeit: Kontingenz - oder Tranzendenzformel des Rechts? Zeitschrift für Rechtssoziologie, n. 29, heft 1. Stuttgart: Lucius \& LuciusVerlagsgeselschaft, p. 9-36.)

16 Lübbe, 1991, p. 174.

17 Jervis, 1976, p. $117-118$.

18 ONUF, 1982, p. 48-49.

19 Franck, M., 1988, p. 725.

20 Somek, 2001.

21 "Wherever such a rule of recognition is accepted, both private persons and officials are provided with authoritative criteria for identifying primary rules of obligation.” (HART. H. L. A.. The concept of law (1961). Second edition. Oxford: Oxford University Press, 1994. p. 100.)

22 Hart, 2000, p. 22.

23 Dworkin, 2002, p. 27-28.

24 "To be sure, the source of every rule - its pedigree, in the terminology of this essay - is one determinant of how strong its pull to compliance is likely to be" (Franck, 1988, p. 705).

25 Maccormick, 2006. p. 300-301.

26 "Pero, aunque mis principales ejemplos de los critérios proporcionados por la regra de reconocimento son custiones a las que Dworkin ha llamado 'pedigri', y se refieram sólo a la manera en la cual las normas son adoptadas o creadas por 
las instituciones jurídicas y no a su contenido, expresamente sostengo tanto en este libro y en mi artículo anterior sobre 'Positivismo y la separación de derecho y moral', que en algunos sistemas de derecho, como en el de Estados Unidos, el último critério de validez jurídico podría explicitamente incorporar, además del pedigrí, principios de justicia o valores morales sustantivos y estos podrían constituir el contenido de límites juridicos constitucionales” (Hart, 2000, p. 22).

27 Franck, 1990, p. 209.

28 Franck, 1988, p. 706.

29 Kennedy, 1988, p. 397-435.

30 "Why should rules, unsupported by an effective structure of coercion comparable to a national police force, nevertheless elicit so much compliance, even against perceived self-interest, on the part of sovereign states?" (Franck, 1988, p. 707).

31 "Admittedly, the rule system of the community of states is far from perfected: absence of rules and disobedience continue to be important dissonant features. But it is too readily assumed that these deficiencies are attributable primarily to the lack of an Austinian sovereign with police powers. The weakness of this explanation is its failure to account for significant deviance: that many rules are obeyed much of the time” (Franck, 1988, p. 710).

32 "In such circumstances, legitimacy is indicated not by obedience, but by the discomfort that disobedience induces in the violator. (Student demonstrations sometimes are a sensitive indicator of such discomfort.)” (Franck, 1988, p. 712).

33 Henkin, 1979, p. 10.

34 Kennedy, 2003, p. 429.

35 Franck, 1988, p. 713-714.

36 Franck, 1988, p. 717.

37 Weiler, 2010, p. 507.

38 Çali, 2009, p. 805 ss.

39 Galindo, 2006, p. 342ss.

40 O texto em inglês determina "(i) Withdrawal of Israel armed forces from territories occupied in the recent conflict"; o texto em francês "Retrait des forces armées israéliennes des territoires occupés lors du récent conflit". A omissão do "the", na versão inglesa, reativa ao "des", na francesa, é uma das bases da disputa semântica.

41 Franck, 1988, p. 716.

42 "Such expectations of reciprocity are important threads in the fabric of the international system; but before an expectation of reciprocity can arise, there must be some mutual understanding of what the rule covers, what events constitute "similar circumstances" (Franck, 1988, p. 717).

43 "The Commission, at its fifty-ninth session (2007), decided to include the topic "Immunity of State officials from foreign criminal jurisdiction" in its program of work and appointed Mr. Roman A. Kolodkin as Special Rapporteur.(...) The Special Rapporteur then turned to the prospective content of his subsequent report. He reiterated his intention to study therein the scope and limits of the immunity of State officials from foreign criminal jurisdiction (both ratione personae and ratione materiae), including the question of possible exceptions to immunity in the case of crimes under international law and official acts unlawfully carried out in the territory of a State exercising jurisdiction. (...) He would also examine the distinction between "official" and "private" acts for the purposes of immunity ratione materiae, notably the question whether the nature or gravity of an unlawful act could affect its qualification as an act carried out in an official capacity" (United Nations. International Law Comission. Report on the work of its sixtieth session (5 May to 6 June and 7 July to 8 August 2008. General Assembly Official Records. Sixty-second Session. Supplement n. 10, A/63/10). 
44 Morgenthau, 2003, p. 483-486.

45 Carty, 1986, p. 113-114.

46 Essas ideias são uma tradução livre a partir da passagem: "In the dazzling light of the desert - at the same site, where Derrida observes the violence of law's self-foundation, where Kelsen had seen the Grundnorm, and Hart the basic rule of recognition - they see the khadi's twelfth camel grazing at a green place. But they quarrel whether the site is an oasis or a Fata Morgana. For them the twelfth camel is not a symbol representing something else, rather it performs itself the symbolic operations of law. It is the localized self-reference of the legal system which ends in the interplay of paralyzing paradoxes and liberating moves" (Teubner, 2001, p. 21).

47 O jurista Marcelo Neves adota a tradução "lícito/ilícito" para a expressão "Recht/Unrecht" da teoria dos sistemas de Niklas Luhman. Neves afirma que a tradução por "direito/não direito" é absurda por tratar-se de uma diferença interna ao sistema jurídico e também recusa a tradução por "legal/ilegal” porque a expressão legalé restrita na língua portuguesa (Neves, 2007, p. XII). Licitude é associada comumente à conduta e não há que se falar em norma ou decisão lícita, pelo menos na língua portuguesa. A tradução por "legal/ilegal” parece ser também adequada por mais bem corresponder ao formalismo luhmaniano. Recentemente, estudos sobre normas produzidas fora do sistema jurídico ou sobre a existência de normas em diferentes planos jurídicos oferecem outras possibilidades interpretativas do binômio luhmaniano. A esse respeito: “A global merchant's law would belong to the multitude of fragmented legal discourses, whether the discourse is of state law, of rules of private justice or regulations of private government that play a part in the dynamic process of the mutual constitution of actions and structures in the global social field. Nor is it the law of nation states but a symbolic representation of validity claims that determines their local, national or global nature" (TEubner, 1997. p. 10). Também: "There is no one "international community'. The phrase refers to he particular elite who are the audience for the global media. We must recognize the idea that they share a 'consensus' view of global political or ethical matters- or that their views condense the attitudes of humanity - as a fantasy." (KENNEDY, Two, Three, many legal orders: legal pluralism and the cosmopolitan dream. op. cit., p. 658)

48 "No doubt, the idea of peremptory norms (jus cogens) is older than modern international law itself. (...) Over the years most of the initial skepticism around the notion itself has tended to vanish" (United Nations. Yearbook of the International Law Commission, 2006, v. II, Part Two, p. 182-183).

49 "It also reflects the influence of Natural Law thinking. Various examples of the content of jus cogens have been provided, particularly during the discussions on the topic in the International Law Commission, such as an unlawful use of force, genocide, slave trading and piracy" (Shaw, 1997, p. 117).

50 "(33) The content of jus cogens. The most frequently cited examples of jus cogens norms are the prohibition of aggression, slavery and the slave trade, genocide, racial discrimination apartheid and torture, as well as basic rules of international humanitarian law applicable in armed conflict, and the right to self-determination. Also other rules may have a jus cogens character inasmuch as they are accepted and recognized by the international community of States as a whole as norms from which no derogation is permitted" (United Nations, Yearbook of the International Law Commission, 2006).

51 Franck, 1988, p. 725.

52 Kennedy, 2003, p. 426-427.

53 Prefere-se a citação literal na língua original do texto em virtude da possibilidade da tradução comprometer o sentido. O exemplo para validação simbólica também merece referência: "The singing of the national anthem, for example, is a vocal and (on public occasions) a visual signal symbolically reinforcing the citizen's relationship to the state, a relationship of rights and duties. This compliance reinforcement need not be spelled out in the actual words of the anthem (as it is not in the commonly used stanza of the American one). The act of corporate singing itself is a sufficient cue to validate the fabric of regularized relationships that are implicated in good citizenship. We are not really singing about bombs bursting in the night air, but about free and secret elections, the marketplace of ideas, the rule of valid laws and impartial judges" (Franck, 1988, p. 725-726.) O exemplo de Frank reforça uma das características do artigo bem como do livro: as reiteradas utilizações de exemplos do comportamento estatal estadunidense. No que atine ao método, a opção do autor de trabalhar com referências empíricas restritas entra em conflito com o objetivo de reforçar hipótese de caráter, supostamente, universal (legitimidade como propriedade da norma). 
54 "Alle prägnanten Begriffe der modernen Staatslehre sind säkularisierte theologische Begriffe" (Schmitt, 2009, p. 43).

55 A prática cotidiana das chancelarias é rica em exemplos como a previsão do art. 20 da Convenção de Viena de 1961 que confere o direito às Missões diplomáticas de utilizar a bandeira e o escudo do Estado acreditante. Assim ocorre também com a rigidez dos cerimoniais ainda minuciosamente observada em funerais, escoltas, visitas oficiais, posses, recepções, etc.

56 Franck, 1988, p. 729.

57 "A new rule will have greater difficulty finding compliance, and even evidence of its good sense may not fully compensate for its lack of breeding. Nevertheless, a new rule may be taken more seriously if it arrives on the scene under the aegis of a particularly venerable sponsor such as a widely ratified multilateral convention, or a virtually unanimous decision of the International Court of Justice" (Franck, 1988, p. 726-727).

58 Franck, 1990, p. 733.

59 Franck, 1988, p. 741.

60 Fögen, 2007, p. 9.

61 Varenneman, 2003, p. 157

62 Varenneman, 2003, p. 168.

63 "This provision confers upon the permanent members the much discussed 'veto right.."(...) "As to the 'equality' of the states, the privileges conferred in Article 27, 108 and 109, upon the states which are permanent members of the Security Council are incompatible with the principle of 'equal rights of nations large ans small' as well as with the principle of 'sovereign equality' of the Members" (Kelsen, 2000, p. 51, 239).

64 "Thus, in the community of nations, each state must treat discrete obligations that arise only under special circumstances, like the obligation to help a friend who is in great financial need, as derivative from and expressing a more general responsibility active throughout the association in different ways. (...) Rules become coherent when they are applied so as to preclude capricious checker boarding. They preclude caprice when they are applied consistently or, if inconsistently applied, when they make distinctions based on underlying general principles that connect with an ascertainable purpose of the rules and with similar distinctions made throughout the rule system. Validated membership in the community accords equal capacity for rights and obligations derived from its legitimate rule system" (Franck, 1988, p. 748-751).

65 Oppenheim, 1955. p. 11-13, 17.

66 "Hart's critique of the community of states as small and primitive is still widely accepted. Even those who think that the system is at a more sophisticated stage of development might well concede that Hart's misgivings are not wholly unjustified. The recurrence of wars, other conflicts and unremedied injustices invites the appellation 'primitive'” (Franck, 1998, p. 752).

67 Franck, 1998, p. 759.

68 De qualquer forma, talvez seja mais acertado admitir que a natureza do direito internacional seja diversa do direito interno dos Estados do que adjetivar a comunidade internacional como 'primitiva' a partir da comparação inadequada com o contexto estatal. Num texto publicado em 1980, Antônio Augusto Cançado Trindade se refere à caracterização da sociedade internacional enquanto primitiva: "há que se examinar com muita cautela e espírito crítico a tese do chamado 'estado primitivo do direito internacional': se há autores respeitáveis que a defendem, como Kelsen, Guggenheim e Scelle, também há os que hoje a rejeitam, como Virally e Ago, concentrando-se nas características essenciais do ordenamento jurídico internacional” (Trindade, 2002. p. 184).

69 Parece não ser apropriado neste texto, descrever a forma como Niklas Luhman compreende o denominado fechamento operativo dos sistemas jurídicos a partir da teorização sobre as operações de reconhecimento sobre o que é jurídico e o que não é. A este respeito, v. Luhman (1995, p. 41ss). 
70 Franck, 1990, p. 209.

71 Kelsen, 1998. p. 9.

72 Hart, 2000. p. 49.

73 Kennedy, 2003, p. 432.

74 FRANCK, The Power of legitimacy among nations. op. cit., p. 210.

75 Rawls, 2008, p. 699.

76 Rawls, 2001, p. 164.

77 "The appeal to moral principles in the international sphere has no universal meaning. It is either so vague as to have no concrete meaning that could provide rational guidance for political action, or it will be nothing but the reflection of the moral perceptions of a particular nation" (Koskenniemi, 2000. p. 23).

78 Koskenniemi, 2000, p. 22.

79 "It is a deadly earnest conflict between an imagined world in which each person is free to pursue his or her individual potential and one in which persons must derive their identities and meanings exclusively in accordance with immutable factors: genetics, territoriality, and culture" (Franck, 2001. p. 10).

80 A citação é somente exemplificativa, pois a blibliografia desse artigo fez referência a outros textos nos quais são tratados os temas da justiça, do jus cogens e dos direitos fundamentais. "Neither interpretation has fully plumbed the depths of the problem of ius cogens posed by a heterarchical order. A hierarchical elevation and subordination of legal orders is an equal anathema to a polycentric global law as is the assumption that an emergent functional regime is an autarkical system operating within a global societal vacuum" (Teubner, 2004. p. 1033).

81 "For nation-building in the past, unity of the law was one of the main political assets - a symbol of national identity and simultaneously a symbol of (almost) universal justice. A worldwide unity of the law, however, would become a threat to legal culture. For legal evolution the problem will be how to make sure that a sufficient variety of legal sources exists in a globally unified law. We may even anticipate conscious political attempts to institutionalize legal variation, for example, at regional levels" (v. Global Bukovina: Legal Pluralism in the World Society, Teubner, 1997, p. 5).

82 "If the fight against cultural exceptionalism is to be made effective, it needs military and fiscal resources. It needs a common strategy involving governments, intergovernmental organizations, NGOS, business, and labor. But let there be no mistake: the fight is essentially one between powerful ideas, the kind that shake the pillars of history" (Franck, 2001, p. 10). ônus (...)”. Para detalhes, v. Milaré (2009, p. 1237-1238).

\section{REFERÊNCIAS BIBLIOGRÁFICAS}

AUSTIN, John. The province of Jurisprudence Determined and The Uses of the Study of Jurisprudence (1832) (1863). Indianápolis/Cambridge: Hackett Publishing Company, 1998.

BANSHOFF, Thomas; SMITH, Mitchell P. Introduction: conceptualizing legitimacy in a contested policy. In: BANSHOFF, Thomas; SMITH, Mitchell P. (Org.) Legitimacy and European Union: the contested policy. New York: Routledge, 2004.

CARTY, Anthony. The Decay of International Law? A reappraisal of the limits of legal imagination in international affairs. Mellend Schill monographs in international law. Manchester: Manchester University Press, 1986.

ÇALI, Basak. On Interpretativism and International Law. The European Journal of International Law, v. 20, n. 3, 2009 . 
DWORKIN, Ronald. Levando os direitos a sério (1977). Tradução de Nelson Boeira. São Paulo: Martins Fontes, 2002.

FÖGEN, Marie Theres. Das Lied vom Gesetz. München: Carl Friederich von Siemens Stiftung, 2007. FONSECA JR., Gelson. A Legitimidade e outras questões internacionais: Poder e ética entre as nações. São Paulo: Paz e Terra, 1998.

FRANCK, Thomas. Legitimacy in International System. The American Journal of International Law, v. 82, n. 4, Oct. 1988.

The Power of legitimacy among nations. New York: Oxford University Press, 1990.

Are the Human Rights universal? Foreign Affairs, v. 80, n. 01. New York: Council on Foreign

Relations, 2001.

GALINDO, George Rodrigo Bandeira. Quem diz humanidade, pretende enganar?: internaconalistas e os usos da noção de patrimônio comum da humanidade aplicada aos fundos marinhos (1967-1994). Tese apresentada ao Curso de Pós-Graduação em Relações Internacionais. Brasília: Instituto de Relações Internacionais, Universidade de Brasília, 2006.

HART, H. L. A. Post scriptum al concepto de derecho (1994). Mexico: Universidad Nacional Autonoma de Mexico, 2000.

HART, H. L. A. The concept of law (1961). Second edition. Oxford: Oxford University Press, 1994.

HENKIN, Louis. How nations behave. 2. ed., New York: Columbia University Press, 1979.

JERVIS, Robert. Perceptions and Misperceptions in International Politics. Princeton: Princeton University Press, 1976, p. 117-118.

KELSEN, Hans. O problema da Justiça (1960). São Paulo: Martins Fontes, 1998.

KELSEN, Hans. The Law of United Nations: a Critical Analysis of Its Fundamental Problems - With Supplement (1950). New Jersey: The Lawbook Exchange, LTI, 2000.

KENNEDY, David. Tom Frank and the Manhattan School. Journal of International Law and Politics, v. 35, n. 2, 2003, p. 397-435.

KENNEDY, David. One. Two, Three, many legal orders: legal pluralism and the cosmopolitan dream. N.Y.U. Review of Law and Social Change Nr. 657, v. 31, n. 64, 2007, p. 641-659.

KOSKENNIEMI, Martii. Carl Schmitt, Hans Morgenthau, and the image of Law in International Relations. In: BYERS, Michael. (Org.) The role of Law in International Politics: Essays in International Relations and International Law. Oxford: Oxford University Press, 2000.

LÜBBE, Weyma. Legitimität kraft Legalität: Sinnvertehen und Institutioneanalyse bei Max Weber und Kritiken. Tübingen: J.C.B. Mohr (Paul Siebeck), 1991.

LUHMAN, Niklas. Das Recht der Gesellschaft (1993). Frankfurt am Main: Suhrkamp, 1995.

MACCORMICK, Neil. Argumentação jurídica e teoria do direito. São Paulo: Martins Fontes, 2006.

MORGENTHAU, Hans. A Política entre as nações: a luta pelo poder e pela paz. São Paulo: Imprensa Oficial do Estado de São Paulo/Editora da Universidade de Brasília/ Instituto de Pesquisa de Relações Internacionais, 2003, p. 483-486.

NEVES; Marcelo. A constitucionalização simbólica. São Paulo: Martins Fontes, 2007.

ONUF, Nicolas Greenwood. Law - Making in the Global Community. Durham: Carolina Academic Press, 1982. OPPENHEIM, Lassa Francis Lawrence; LAUTERPACHT, H. International Law: a Treatise. Vol. I - Peace. (1912). 8. ed. Great Britain: Longmans, Green and Co., 1955.

RAWLS, John. Uma teoria da justiça (1971). São Paulo, Martins Fontes, 2008.

RAWLS, John. O direito dos povos. São Paulo: Martins Fontes, 2001.

ROBERTS, Anthea Elizabeth. Traditional and Modern approaches to customary international law: a reconciliation. American Journal of International Law, v. 95, 2001, p. 757-791. Disponível em:

www.asil.org/ajil/roberts.pdf. Acesso em: nov. 2011.

SCHMITT, Carl. Politische Theologie. Vier Kapitel zur Lehre von der Souveranität (1922). Neunte Auflage. Berlin: Duncker \& Humblot, 2009.

SHAW, Malcom N. International Law. $4^{\text {th }}$ ed. United Kingdom: Cambridge University Press, 1997. SOMEK, Alexander. Kelsen Lives. The European Journal of International Law, v. 18, n. 3, p. 409-451, 2001. TEUBNER, Gunther. Global Law without a State. Darmouth Publishing Co. Ltd. Aldershot, 1997. TEUBNER, Gunther. Selbstsubversive Gerechtigkeit: Kontingenz- oder Tranzendenzformel des Rechts? Zeitschrift für Rechtssoziologie, n. 29, heft 1. Stuttgart: Lucius \& LuciusVerlagsgeselschaft.

TEUBNER, Gunther. Alienating justice: on the surplus value of the twelfth camel. In: NELKEN, David; PRIBÁN, Jirí. (Eds.) Lawe's New Boundaries: Consequences of Legal Autopoiesis. Ashgate: Aldershot, 2001. TEUBNER, Gunter; FISHER-LESCANO, Andreas. Regime - Colisions: The vain search for legal unity in the fragmentation of global law. Michigan Journal of International Law, v. 25, n. 999, p. 999-1046, Summer 2004. 
TRINDADE, A. A. C. Apontamentos sobre o uso das ficções no direito internacional. In: O Direito Internacional em um mundo em transformação. Rio de Janeiro: Renovar, 2002.

UNITED NATIONS. International Law Commission. Report on the work of its sixtieth session (5 May to 6 June and 7 July to 8 August 2008). General Assembly Official Records. Sixty-second Session. Supplement n. 10 (A/63/10). Disponível em: http: / / untreaty.un.org/ilc/reports/2008/2008report.htm. Acesso em: 18 nov. 2008 UNITED NATIONS. Conclusions of the work of the Study Group on the Fragmentation of International Law: Difficulties arising from the Diversification and Expansion of International Law Adopted by the International Law Commission at its Fifty-eighth session, in 2006, and submitted to the General Assembly as a part of the Commission's report covering the work of that session (A/61/10, paragraph 251). In: Yearbook of the International Law Commission, 2006, vol. II, Part Two, p. 182-183. VARENNEMAN, Jean-Michel. História da África. In: PROCÓPIO, Argemiro. (Org.) Brasil: parcerias estratégicas. São Paulo: Editora Alfa-Omega, 2003.

WEBER, Max. Economia e Sociedade. 4. ed. Brasília: Editora Universidade de Brasília, 2004.

WEILER, J.H.H. The Interpretation of Treaties - a reexamination: The European Journal of International Law, v. 21, n. 3, 2010.

Felipe Kern Moreira

Departamento de Relações Internacionais da UFRR

Campus Paricarana

Av. Capitão Ene Garcês, n. 2413 - Bloco I - Sala 150

Bairro Aeroporto - 69304-000

Boa Vista - RR - Brasil

felipe.kernagmail.com

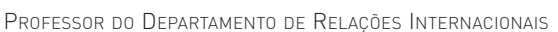
DA UnIVERsidade FEDERAL dE RORAIMA (UFRR) 